\title{
Turbulent Film Condensation on a Horizontal Elliptical Tube with Variable Wall Temperature
}

\author{
Yan-Ting Lin \\ Postgraduate student, Department of Mold and Die Engineering, National Kaohsiung University of Applied Sciences, \\ Kaohsiung, Taiwan 807. \\ Sheng-An Yang \\ Professor, Department of Mold and Die Engineering, National Kaohsiung University of Applied Sciences, Kaohsiung, \\ Taiwan 807., samyang@cc.kuas.edu.tw
}

Follow this and additional works at: https://jmstt.ntou.edu.tw/journal

Part of the Engineering Commons

\section{Recommended Citation}

Lin, Yan-Ting and Yang, Sheng-An (2004) "Turbulent Film Condensation on a Horizontal Elliptical Tube with Variable Wall Temperature," Journal of Marine Science and Technology. Vol. 12: Iss. 4, Article 9.

DOI: $10.51400 / 2709-6998.2250$

Available at: https://jmstt.ntou.edu.tw/journal/vol12/iss4/9

This Research Article is brought to you for free and open access by Journal of Marine Science and Technology. It has been accepted for inclusion in Journal of Marine Science and Technology by an authorized editor of Journal of Marine Science and Technology. 


\section{Turbulent Film Condensation on a Horizontal Elliptical Tube with Variable Wall Temperature}

\section{Acknowledgements}

Funding for this study was provided by National Science Foundation, Taiwan, R.O.C. under the grant number NSC93-2212-E-151-002. 


\title{
TURBULENT FILM CONDENSATION ON A HORIZONTAL ELLIPTICAL TUBE WITH VARIABLE WALL TEMPERATURE
}

\author{
Yan-Ting Lin* and Sheng-An Yang**
}

Key words: turbulent, tube, ellipticity, film condensation, variable wall temperature.

\section{ABSTRACT}

An analytical model has been developed for the study of turbulent film condensation from downward flowing vapors onto a horizontal elliptical tube with variable wall temperature. The interfacial shear at the vapor condensate film is evaluated with the help of Colburn analogy. The condensate film flow and local/or mean heat transfer characteristics from a horizontal elliptical tube with nonuniform temperature variation under the effect of Froude number, sub-cooling parameter and system pressure parameter has been conducted. Although the non-uniform wall temperature variation has an appreciable influence on the local film flow and heat transfer; however, the dependence of mean heat transfer on the non-uniform wall temperature variation is almost negligible.

\section{INTRODUCTION}

Film-wise condensation heat transfer is widely used in power plant system, air-conditioning equipment, and much other chemical industrial process equipment. For laminar film condensation with constant properties and ignoring the vapor velocity, the assumption of the simple Nusselt theory (Nusselt 1916) have been provided in later and more complete studies to be basically accurate. Shekriladze and Gomelauri (1966) first considered forced convection film condensation from a vapor flowing downward to a horizontal circular tube, and obtained numerical solutions by utilizing the asymptotic shear stress at the interface. Rose (1984), Memory et al. (1993; 1995) and Michael et al. (1989) investigated the forced convection laminar condensation on a horizontal tube in experimental data and theoretical analysis. They found the agreement be-

Paper Submitted 08/09/04, Accepted 10/14/04. Author for Correspondence: Sheng-An Yang. E-mail: samyang@cc.kuas.edu.tw.

*Postgraduate student, Department of Mold and Die Engineering, National Kaohsiung University of Applied Sciences, Kaohsiung, Taiwan 807.

**Professor, Department of Mold and Die Engineering, National Kaohsiung University of Applied Sciences, Kaohsiung, Taiwan 807. tween the two to be very satisfactory.

As far as enhancing film condensation is concerned, a horizontal elliptical tube with its major axis aligned in a gravitational direction can serve to thin the condensate film not only through surface tension (manifested by the curvature of surface) but also through an increased effect of gravity as a result of placing a larger proportion of the condensing surface in line with the vertical. Yang and Hsu $(1997,1999)$ further studied the gravity effect, pressure gradient effect, and vapor shear effect on film flow and heat transfer, due to curvature of mixed convection laminar film condensation on a horizontal elliptical tube for variable ellipticities, $e$. They found that for fixed conditions, the mean Nusselt number increases as the value of $e$ increases. However, these works for horizontal configuration do not deal with flow regimes involving wavy condensate or turbulent vapor.

For the condensate film of high velocity vapor flow around a cylinder tube, Michael et al. (1989) presented that the condensate film can be under a turbulent regime. Sarma et al. (1998) used Kato's model (Kato et al., 1968) of eddy diffusivity in the condensate film and assumed that the friction coefficient at liquid vapor interface is identical to that in vapor flow, and found that their results were in good agreement with experimental data relating to the condensation of steam flowing under a turbulent regime. More recently, Homescu and Panday (1999) used an implicit scheme to solve the film condensation on an isothermal horizontal tube under pure vapors flowing vertically and obtained the numerical solution of coupled liquid-vapor interface for Kato's model (Kato et al., 1968) in liquid phase and Pletcher's model in vapor phase.

There are several studies concerning the effect of the non-uniform wall temperature variation on laminar forced convection film condensation, like in circular tube by Memory et al. (1993) and Hsu and Yang (1999), in elliptical tube by Yang and Hsu (1999). But, few studies on turbulent film condensation concerning the effect of wall temperature variation have been pre- 
sented so far.

To consider more general wall temperature condition other than the isothermal wall case presented by Lin and Yang (2004), the present paper investigates in more detail the effect of the wall temperature variation on the turbulent film condensation from downward flowing vapors onto a horizontal elliptical tube. Our major aim is to extend the work of Sarma et al. (1998), which regarding turbulent convection film condensation on a circular tube into that on an elliptical tube by further inclusion of the non-uniform wall temperature variation effect. Besides, instead of a fixed $\mathrm{n}$ (power of Reynolds) value in Sarma et al. (1998), the appropriate $n$ for various vapor velocities has been adopted for analysis in the present study.

\section{ANALYSIS}

Consider a pure saturated vapor at temperature $T_{s a t}$ and at uniform velocity $u_{\infty}$, flowing downward over a horizontal elliptical tube with its major axis " $2 a$ " oriented in the direction of gravity, as seen in Fig. 1. The non-uniform wall surface temperature $T_{w}$ is below the saturation temperature. Thus, condensation occurs on the wall and a continuous film of liquid condensate runs downward over the tube under the combined effects of gravity and interfacial vapor shear. Similar to Sarma et al. (1998), one may assume that condensate film can be under turbulent regime for very high velocity of vapor flow.

As seen in Yang and Hsu's studies (Yang and Hsu, 1997a, b, 1999), the physical model under consideration

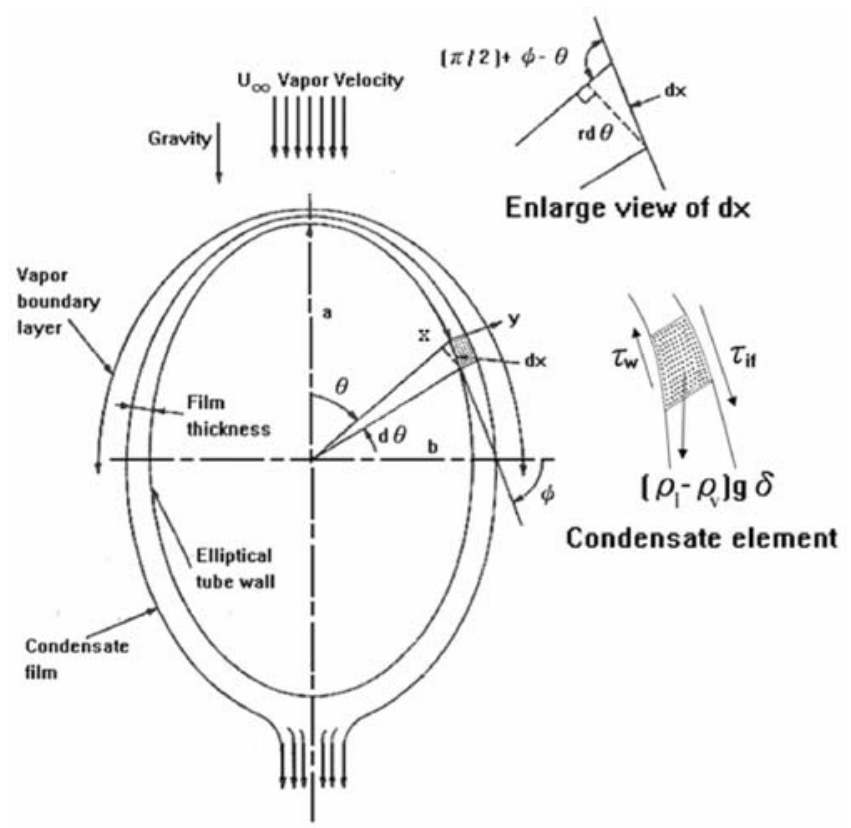

Fig. 1. Physical model and coordinate system. is also shown in Fig. 1, where the curvilinear coordinate $(x, y)$ are aligned along the elliptical wall surface and its normal and $\varphi(x)$ is the angle between the normal to gravity and which tangent to the outer tube wall at the position $(r, \theta)$. The boundary layer approximated energy equation for the steady condensate film flow gives

$$
\bar{u} \frac{\partial \bar{T}}{\partial x}+\bar{v} \frac{\partial \bar{T}}{\partial y}=\frac{d}{d y}\left[\left(\alpha+\varepsilon_{H}\right) \frac{d \bar{T}}{d y}\right]
$$

The momentum equation in conjunction with force balance can be arranged as

$$
\tau_{w}=g \delta\left(\rho_{l}-\rho_{v}\right) \operatorname{Sin} \phi+\tau_{\delta}
$$

At the interface the phase transformation is given by the condition.

$$
\left.\frac{d}{d x} \int_{0}^{\delta} \rho_{l} u d y=\frac{k_{l}}{h_{f g}} \frac{d \bar{T}}{d y}\right]_{y=0}
$$

It is noted here, Eq. (2), reflects a force balance of gravity, wall shear and interfacial vapor shear effects. Eq. (3) is the energy balance between the latent heat released at the interface through conduction of condensate film to the wall surface.

Introducing a parameter $e=\sqrt{a^{2}-b^{2}} / a$, called an ellipticity of the ellipse, as seen in Yang and Hsu's studies (1997a, b; 1999), one may derive the differential stream wise length in terms of $e$ in following relationship

$$
d x=a\left(1-e^{2}\right) d \phi /\left(1-e^{2} \sin ^{2} \phi\right)^{3 / 2}
$$

Thus, inserting Eq. (4) into Eq. (3) yields

$$
\left.\frac{\left(1-e^{2} \sin ^{2} \phi\right)^{3 / 2}}{\left(1-e^{2}\right)} \frac{\partial}{\partial \phi} \int_{0}^{\delta} \rho_{l} u d y=\frac{k_{l}}{h_{f g}} a \frac{\partial \bar{T}}{\partial y}\right)_{y=0}
$$

For a circular cylinder in external flow, the mean Nusselt number can be stated in terms of Prandtl and Reynolds number by using a semi-empirical equation, as seen in Incropera and DeWitt (1990).

$$
\overline{N u}=C \operatorname{Re}_{v}{ }^{n} \operatorname{Pr}^{1 / 3}
$$

where the constants $C$ and $n$ are listed in Table1.

According to Yang and Hsu's works for forced convection film condensation (Yang and Hsu, 1997ab, 1999), the semi-empirical equation for the heat transfer in the flow parallel to a moderately curved surface may also apply to that in the flow on a horizontal elliptical tube.

Further, using Colburn's analogy, one has 
Table 1. Values of $\boldsymbol{C}$ and $\boldsymbol{n}$ in equation (6)

\begin{tabular}{ccc}
\hline Reynolds & $C$ & $n$ \\
\hline $0.4-4$ & 0.989 & 0.330 \\
$4-40$ & 0.911 & 0.385 \\
$40-4000$ & 0.683 & 0.466 \\
$4000-40000$ & 0.193 & 0.618 \\
$40000-400000$ & 0.0266 & 0.805 \\
\hline
\end{tabular}

$\left[\frac{\overline{N u}}{\operatorname{Re}_{v} \operatorname{Pr}}\right] \operatorname{Pr}^{2 / 3}=f / 2$

From Eq. (6) and Eq. (7), we have the mean friction coefficient as

$$
f=2 C \operatorname{Re}_{v}{ }^{n-1}
$$

As mentioned in the result calculated by Homescu and Panday (1999) and Sarma et al. (1998) assumption, they define local friction coefficient in terms of a sinusoid function for a circular tube. Since a circular tube is a special kind of elliptical tubes, we may assume the similar frictional coefficient profile as follows:

$$
f_{\phi}=C \pi\left(\operatorname{Re}_{v}{ }^{n-1}\right) \sin \phi
$$

The local skin shear stress is defined as

$$
\tau_{\delta}=\frac{1}{2}\left(\rho_{v}\right)\left(u_{e}^{2}\right) f_{\phi}
$$

Using potential flow theory for a uniform flow with velocity $u_{\infty}$ past an elliptical tube, one may derive the vapor velocity at the edge of boundary layer as

$$
u_{e}=u_{\infty}\left(1+\sqrt{1-e^{2}}\right) \operatorname{Sin} \phi
$$

From the Eqs. (9), (10) and (11) the liquid-vapor interfacial shear stress can be obtained as.

$$
\tau_{\delta}=2^{-1}(C)(\pi)\left(\rho_{v}\right)\left(u_{\infty}^{2}\right)\left(1+\sqrt{1-e^{2}}\right)^{2}\left(\operatorname{Re}_{v}^{n-1}\right) \operatorname{Sin}^{3} \phi
$$

Finally, Eq. (2) is rewritten as follows

$$
\begin{aligned}
\tau_{w} & =g \delta\left(\rho_{l}-\rho_{v}\right) \operatorname{Sin} \phi+2^{-1}(C)(\pi)\left(\rho_{v}\right)\left(u_{\infty}^{2}\right)(1 \\
& \left.+\sqrt{1-e^{2}}\right)^{2}\left(\operatorname{Re}_{v}^{n-1}\right) \operatorname{Sin}^{3} \phi
\end{aligned}
$$

Since the condensate film is sufficiently close to the solid wall, the turbulent conduction across the con- densate film is more significant than the convective component. As mentioned in Bejan (1995), the energy equation (Eq. (1)) reduces to.

$$
\frac{d}{d y}\left[\left(\alpha+\varepsilon_{H}\right) \frac{d \bar{T}}{d y}\right]=0
$$

subjected to the following boundary conditions

$$
\begin{aligned}
& T=T_{w} \text { at } y=0 \\
& T=T_{\text {sat }} \text { at } y=\delta
\end{aligned}
$$

Assuming the turbulent Prandtl number $\left(\operatorname{Pr}_{t}=\varepsilon_{M} /\right.$ $\varepsilon_{H}$ ) equals unity in Eq. (14) yields.

$$
\frac{d}{d y}\left[\left(1+\frac{\varepsilon_{M}}{v_{l}} \operatorname{Pr}\right) \frac{d \bar{T}}{d y}\right]=0
$$

By introducing the dimensionless groupings, Eqs. (5), (13) and (17) can be restated as follows.

$$
\begin{aligned}
& \frac{d}{d y^{+}}\left[\left(1+\frac{\varepsilon_{M}}{v_{l}} \operatorname{Pr}\right) \frac{d T^{+}}{d y^{+}}\right]=0 \\
& \frac{\left(1-e^{2} \operatorname{Sin}^{2} \phi\right)^{3 / 2}}{\left(1-e^{2}\right)} \frac{\partial}{\partial \phi} \int_{0}^{\delta^{+}}\left(u^{+}\right) d y^{+} \\
& =(S)\left(\operatorname{Re}^{*}\right)\left(G r^{1 / 3} \frac{d T^{+}}{d y^{+}}\right)_{y^{+}=0} \\
& \left(\operatorname{Re}^{*}\right)=\delta^{+} \operatorname{Sin} \phi+\left(\operatorname{Re}^{*}\right)(\varphi)(F r)^{(n+1) / 2} \frac{\left(1+\sqrt{1-e^{2}}\right)^{2}}{4} \operatorname{Sin}^{3} \phi
\end{aligned}
$$

with dimensionless boundary conditions for Eq. (18) as follows:

$$
\begin{aligned}
& T^{+}=0 \text { at } y^{+}=0 \\
& T^{+}=1 \text { at } y^{+}=\delta^{+}
\end{aligned}
$$

In order to obtain the temperature gradient in the close vicinity of the tube, we refer to the Kato's expression (Kato et al., 1968) for eddy diffusivity,

$$
\frac{\varepsilon_{M}}{v_{l}}=0.4 y^{+}\left[1-\exp \left(-0.0017 y^{+2}\right)\right]
$$

Then, specifying or fitting the wall temperature distribution from measured data, one can then calculate the mean wall temperature, as reviewed in Yang and Hsu (1999); 


$$
\bar{T}_{w}=\int_{0}^{\pi} T_{w}(\phi) d \phi / \pi
$$

and derive the temperature difference across the film in the usual manner , as reviewed in Hsu and Yang's model (Hsu and Yang, 1999) ; Memory et al. (1993)

$$
\Delta T=\left(\bar{T}_{s a t}-\bar{T}_{w}\right)(1-A \cos \phi)=\overline{\Delta T}(1-A \cos \phi)
$$

where, $A$ is a constant $(0 \leq A \leq 1)$ and denotes the wall temperature variation amplitude. Combining Eqs. (18), (24), (25) and (26) to eliminate the temperature gradient for situation at the elliptical tube closed to the wall yields

$$
\left.\frac{\partial T^{+}}{\partial y}\right)_{y^{+}=0}=(1-A \cos \phi)\left\{1+\operatorname{Pr}\left[\frac{\varepsilon_{M}}{v_{l}}\right]\left[\int_{0}^{\delta^{+}} \frac{d y^{+}}{1+\operatorname{Pr}\left[\frac{\varepsilon_{M}}{v_{l}}\right]}\right]\right\}^{-1}
$$

Before proceeding to obtain the solution of Eq. (19) and thence to calculate the velocity profile in condensate film, according to the Sarma et al.'s study (1998), the universal velocity distribution is being used in the estimation of discharge rate of the condensate at any angular location. So we may assume that $\tau_{\delta}$ is of the same order as $\tau_{w}$ and be considered as a valid approximation. As seen in Bejan (1995), the velocity profile of condensate film can be obtained from

$$
\frac{\partial u^{+}}{\partial y^{+}}=\left(1+\varepsilon_{M} / v_{l}\right)^{-1}
$$

with the boundary condition at

$$
u^{+}=0 \text { at } y^{+}=0
$$

Since the temperature distribution of condensation film is linear, Fourier's law may be used to express the surface heat flux as

$$
\left.k_{l} \frac{d T}{d y}\right|_{y=0}=h\left(\bar{T}_{s a t}-\bar{T}_{w}\right)
$$

As in Nusselt's theory, the dimensionless local heat transfer coefficient may be expressed as

$$
N u=\left.R e^{+} \frac{d T^{+}}{d y^{+}}\right|_{y^{+}=0}
$$

and

$$
\left.\frac{N u}{\operatorname{Re}_{l}^{1 / 2}}=\frac{\partial T^{+}}{\partial y^{+}}\right)_{y^{+}=0}\left(\operatorname{Re}^{*}\right)\left(\frac{G r^{1 / 3}}{F r}\right)^{\frac{1}{4}} \sqrt{2}
$$

We are also interested in an expression for the overall mean heat transfer coefficient. The Integrals of Eqs. (31) and (32) become.

$$
\overline{N u}=\int_{0}^{\pi} N u\left(1-e^{2} \sin ^{2} \phi\right)^{\frac{-3}{2}} d \phi / \int_{0}^{\pi}\left(1-e^{2} \sin ^{2} \phi\right)^{\frac{-3}{2}} d \phi
$$

and

$$
\frac{\overline{N u}}{\operatorname{Re}_{l}^{1 / 2}}=\frac{\left.\sqrt{2}\left(\frac{G r^{1 / 3}}{F r}\right)^{\frac{1}{4}} \int_{0}^{\pi} \frac{\partial T^{+}}{\partial y^{+}}\right)_{y^{+}=0}\left(\operatorname{Re}^{*}\right)\left(1-e^{2} \sin ^{2} \phi\right)^{\frac{-3}{2}} d \phi}{\int_{0}^{\pi}\left(1-e^{2} \sin ^{2} \phi\right)^{\frac{-3}{2}} d \phi}
$$

\section{NUMERICAL METHOD}

To start the calculation, we assume that the dimensionless condensate film thickness and the liquid film velocity at the upper stagnation point of elliptical tube to be zero, initially. Then, the next liquid film thickness and velocity are obtained by using the dimensionless governing equations (18), (19) and (20).

For a given condition, a brief outline of the solution procedure is given as follows:

(1) Indicate the fixed physically environment parameters of $S, F r, G r, A$ and $e$.

(2) The dimensionless film thickness and velocity profiles are assumed to be zero $\left(\delta^{+}=0, u^{+}=0\right)$ for the node $i=1$ at the upper stagnation point.

(3) Substituting $\Delta \phi=\pi / 500$ and $\left.\partial T^{+} / \partial y^{+}\right)_{y^{+}=0}$ into Eq. (19) and Eq. (20).

Then using the Newton's method for different $\Delta \delta^{+}$ to iterate till the following convergence criteria are satisfied.

$$
\begin{aligned}
& \left\{\left(\operatorname{Re}^{*}\right)^{3}-\delta^{+} \operatorname{Sin} \phi-\left(\operatorname{Re}^{*}\right)(\varphi)(F r)^{(n+1) / 2} \frac{\left(1+{\sqrt{1-e^{2}}}^{2}\right.}{4} \operatorname{Sin}^{3} \phi\right\} \\
& \quad \leq 10 e-6
\end{aligned}
$$

and

$$
\operatorname{Re}^{*}=\frac{\left(1-e^{2} \operatorname{Sin}^{2} \phi\right)^{3 / 2}}{\left.\left(1-e^{2}\right)\left(G r^{1 / 3}\right)(S) \frac{\partial T^{+}}{\partial y^{+}}\right)_{y^{+}=0}} \frac{\partial}{\partial \phi} \int_{0}^{\delta^{+}}\left(u^{+}\right) d y^{+}
$$

where

$$
\left.\frac{\partial}{\partial \phi} \int_{0}^{\delta^{+}}\left(u^{+}\right) d y^{+}=\frac{\Delta \delta^{+}}{\Delta \phi}\left[u_{i}^{+}+\frac{u_{i}^{+}}{2} \frac{\partial u^{+}}{\partial y^{+}}\right)_{y^{+}=\delta^{+}}\right]
$$


(4) When the increment of dimensionless film thickness $\left(\Delta \delta^{+}\right)$for node $i=i+1$ is convergent, the next film thickness for node $i=2$ is expressed as $\delta_{i+1}^{+}=\delta_{i}^{+}+\Delta \delta^{+}$and its corresponding angle $\phi_{i+1}=\phi_{i}+\pi / 500$.

(5) Repeating above calculations from step-3 to step-4 to find out all the needed values up to $\phi=\pi$. Finally, both the dimensionless local and mean Nusselt numbers are determined from Eq. (32) and Eq. (34).

\section{RESULTS AND DISCUSSION}

Two parts: hydrodynamics of condensate film flows and characteristics of condensation heat transfer are presented and discussed in this section.

\section{Flow hydrodynamics of condensate film}

Figures $2 \mathrm{a}, 2 \mathrm{~b}$ and $2 \mathrm{c}$ show the dimensionless film thickness profiles around the periphery of elliptical tube for different parameters including non-uniformity variation amplitude $A, n$ (power of Reynolds), ellipticity e, and Froude number.

When $e=0$ (circular tube) and $A=0$ (isothermal wall), the dimensionless local film thickness profile coincides with Sarma et al. (1998) in Fig. 2a and b. We take the wall temperature variation amplitude as " $1-A$ $\cos \phi^{\prime \prime}$ instead of " 1 " (isothermal case) to evaluate $\partial T^{+}$/ $\left.\partial y^{+}\right)_{y^{+}=0}$ in Eq. (27). This leads to a smaller $\delta^{+}$for $A \neq$ 0 cases on Eq. (19). Hence, the local film thickness profile for $A \neq 0$ is smaller than that for $A=0$, as seen in Figs. $2 \mathrm{a}$ and $2 \mathrm{~b}$.

Since the larger value of sub-cooling parameters "S" will enhance the larger condensate mass flow occurring, hence, the condensate film thickness $\delta^{+}$increases with the value of $S$ in Eq. (19), as seen in Fig. 2a. A larger value of $\mathrm{Fr}$ i.e. a higher velocity of vapor flow will lead to a higher condensate mass flow rate. Hence, the condensate film thickness increases with $F r$, as seen in Fig. 2c.

As $e$ approaches unity, $\delta^{+}$becomes thinner due to the more favorable pressure gradient effect for a larger $e$, as seen in Fig. 2b. For different values of $n$, Fig. $2 \mathrm{c}$ shows that the condensate film thickness for laminar vapor flow zone (with low value of $n$ ) is smaller than that for turbulent vapor flow zone (with high value of $n$ ).

\section{Characteristics of heat transfer}

\section{(1) Profile of the local heat transfer}

From the thermal point of view, Figs. $3 \mathrm{a}, 3 \mathrm{~b}$ and $3 \mathrm{c}$ show the influences of $S, F r, e, A$, and $n$ upon the local heat transfer coefficients, respectively. With reference

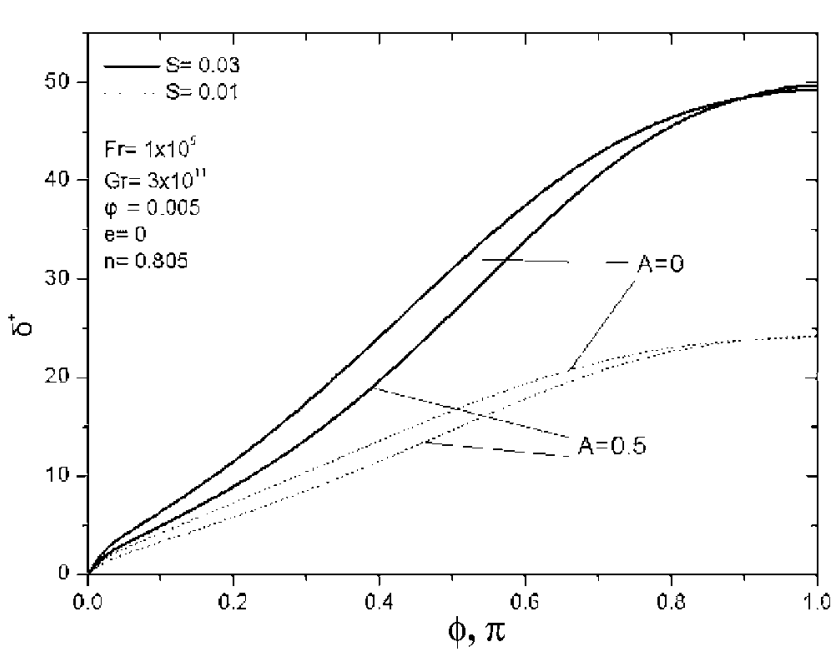

(a)
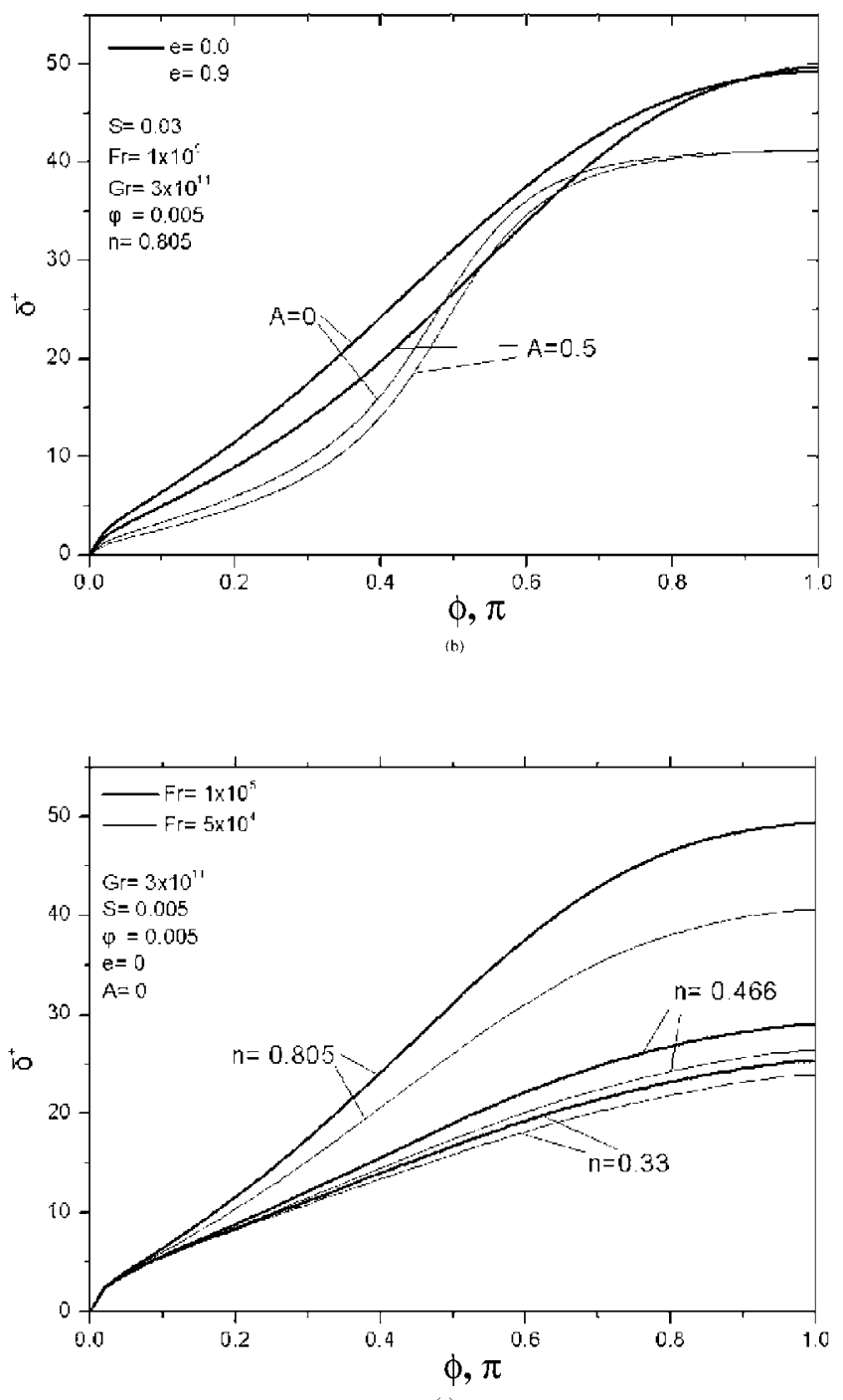

Fig. 2. Dimensionless local film thickness around periphery of ellipse. 
to Eq. (19) and Eq. (32), one may see that when $\phi=\pi /$ 2 around; $N u$ reaches a maximum value. When $n=$ 0.805 in Fig. 3a, $e=0$ in Fig. $3 b$, and $A=0$ in Fig. 3c, the corresponding result agrees with Sarma et al. (1998). Further, as $n$ is increasing, the local heat transfer coefficient is decreasing due to its film thickness increasing as in Fig. 3a.

According to Asbik et al. (2003), the transition angle usually occurs around $35 \pm 20$ degrees; depending on the value of $F r$. This point can be easily seen in Fig. $3 \mathrm{~b}$. Before the critical transition angle $\phi_{c}=0.2 \pi$, the film flow belongs to the laminar flow zone. Hence, the local Nusselt number is increasing with $e$ due to $\delta^{+}$ decreasing with $e$. beyond the critical transition angle $\phi_{c}(=0.2 \pi)$, the condensate film flow usually locates within the turbulent flow zone. From Eq. (32), $\mathrm{Nu}$ is proportional to $\mathrm{Re}^{+}$in terms of shear velocity $u^{*}$. Shear stress $\tau_{w}$ decreases with increase in $e$ in Eq. (13), because the skin friction coefficient $C_{f}$ of elliptical body decreases with an increasing $e$. Further $\mathrm{Re}^{+}$decreases with $u^{*}$. Beside, $\left.\partial T^{+} / \partial y^{+}\right)_{y^{+}}=0$ can be proved to be insignificant variation with $e$. Thus, $N u$ decreases with $e$, as seen in Fig. $3 b$.

From Eq. (32), one may see the $\left.\partial T^{+} / \partial y^{+}\right)_{y^{+}}=0$ depends on " $1-A \cos \phi$ ". As $1-A \cos \phi$ decreases with $A$ before $\phi=\pi / 2$, the local dimensionless heat transfer coefficient becomes smaller than that for $A=0$. When $\phi$ exceeds $\pi / 2$, this situation becomes upside-down, as seen in Fig. 3c.

\section{(2) Performance of the mean heat transfer}

In Fig. 4, as the interfacial shear parameter $\varphi$ increases, i.e. the system operating pressure increases, the mean heat transfer coefficient increases for $e=0$ (Sarma's case), $e=0.5$ and $e=0.9$. It is to be noted that the mean heat transfer coefficient is much more dependant on the system pressure in the vapor velocity region due to the onset of turbulent in the condensate film. Meanwhile, for a given value of $S$, increase in $F r$ will lead to increase in the mean heat transfer coefficient, which apply to $e=0,0.5$ and 0.9 .

In Fig. 5, it is obviously seen that the mean heat transfer coefficient decreases with increase in $S$ for $e=$ 0 (Sarma case) and $e=0.5$. This trend can be explained from Fig. $3 b$ and $3 c$, i.e. because the local heat transfer coefficient decreases with increase in $S$ around the periphery of tube.

In Fig. 6, for fixed values of $\mathrm{Fr}$ and $S$, when order of $F$ is greater than 1.0, Yang and Hsu's solutions (Yang and Hsu, 1999) solutions from $e=0$ to 0.9 tend to blend with Nusselt-type condensation. As $F$ is increasing (lower velocity of vapor), the present result using turbulent model $(n=0.33)$ at $e=0$, is larger than Yang and
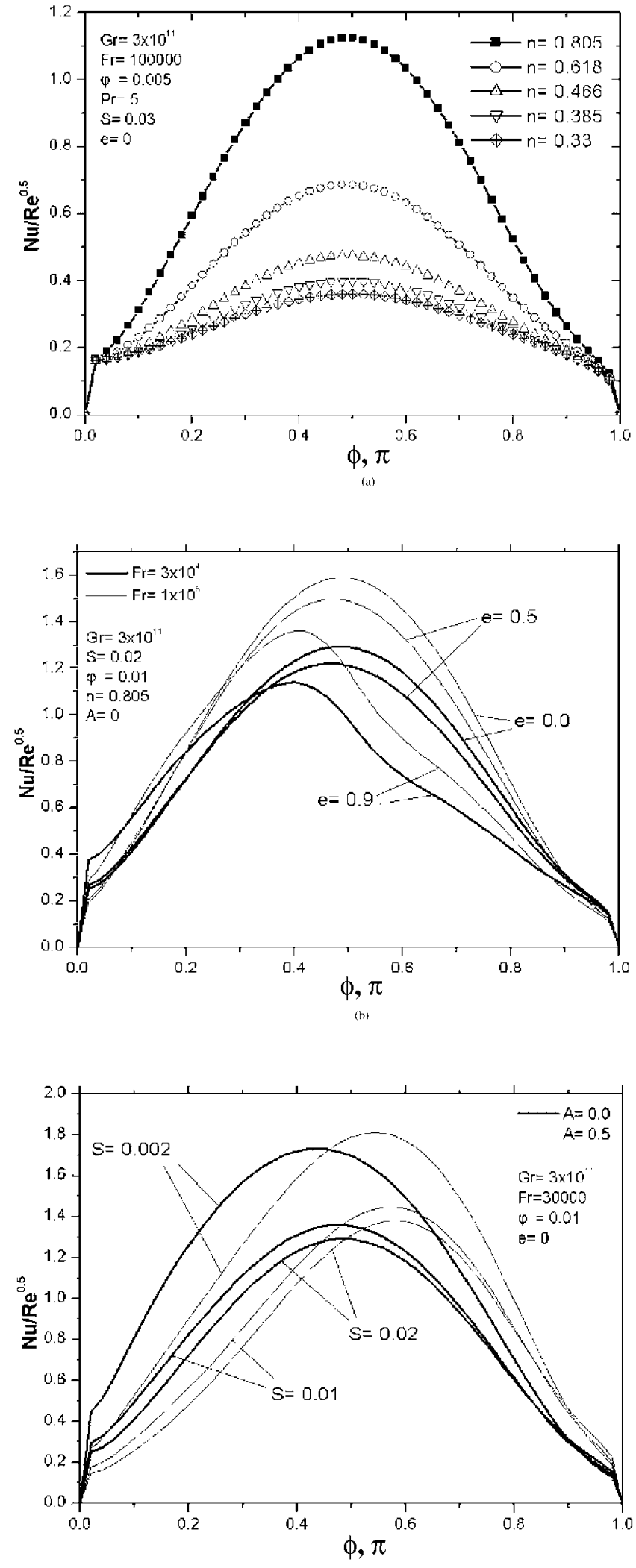

(c)

Fig. 3. Dimensionless the local Nusselt number around periphery of ellipse. 
Hsu's solution by $8.6 \%$ around. This difference is caused by eddy thermal effect. However, both models show a similar uptrend with an increase in $F$.

In Fig.7, for the range $F<1.0$, i.e. higher velocity of vapor flow, it is obviously seen that the present result shows a downtrend with increase in F instead of nearly constant values for laminar model by Yang and Hsu's solution (Yang and Hsu, 1999). For a circular tube ( $e=$ $0)$, the present result also shows in a good agreement with Michael et al.'s experimental data (Michael et al., 1989) as Sarma et al. (1998) did.

Figure 8 shows that, in general, the mean Nusselt number increases insignificantly with $A$ regardless the values of $F$. For an elliptical tube with $e=0.5$, as $A$ increases to unity, the mean heat transfer coefficient decreases to $3.96 \%$ for $F=10,3.04 \%$ for $F=1.0$ and

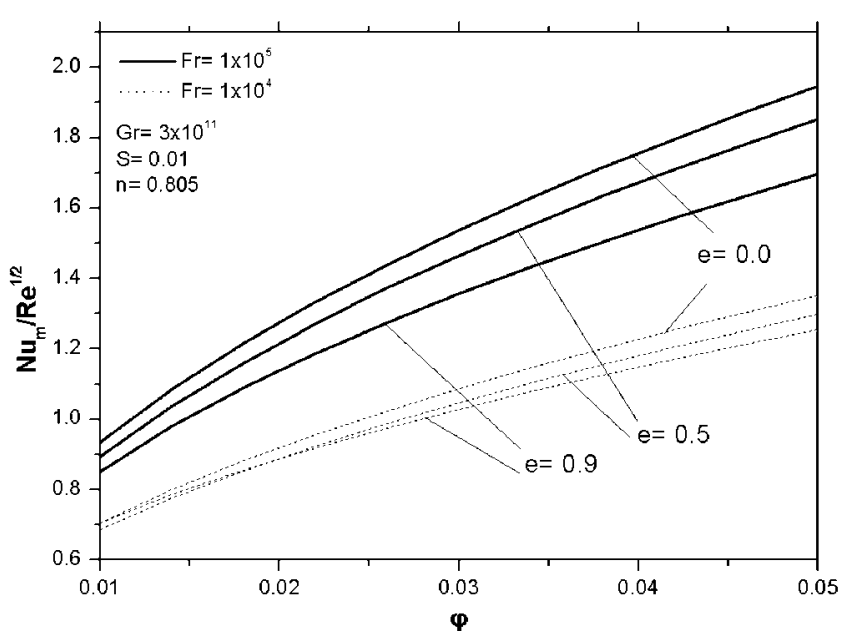

Fig. 4. Effect of on the mean Nusselt number.

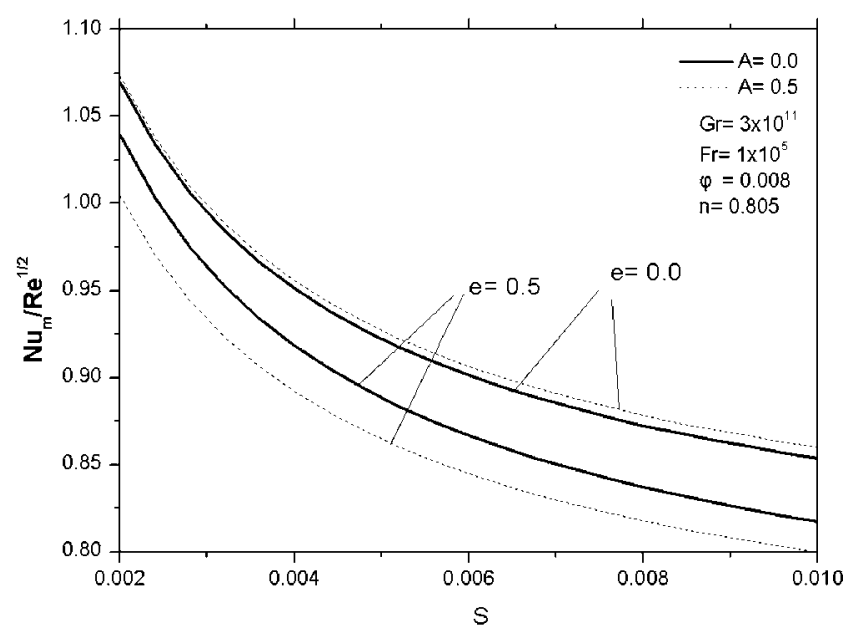

Fig. 5. Effect of $S$ on the mean Nusselt number.

\section{$2.78 \%$ for $F=0.1$, respectively.}

In Fig. 9, as e increases to 0.9, the mean heat transfer coefficient decreases to $13.9 \%$ for $F=0.001$ and $8.01 \%$ for $F=0.01$, respectively. But for $F=0.1$, it increases to $4.63 \%$. Next, for natural film condensation dominated case, the mean heat transfer coefficient increases to $18.6 \%$ for $F=1,21.7 \%$ for $F=10$, and $22.2 \%$ for $F=100$, respectively. In practical applications, for lower velocity of vapor flow (or higher $F$ ), the mean heat transfer coefficients for elliptical tubes (with major axis oriented in gravity) are lager than that for a circular tube, as seen in Fig. 9. However, for higher velocity of vapor flow (or lower $F$ ), the mean heat transfer characteristics for a circular tube is better than that for an elliptical tube (with major axis oriented in gravity).

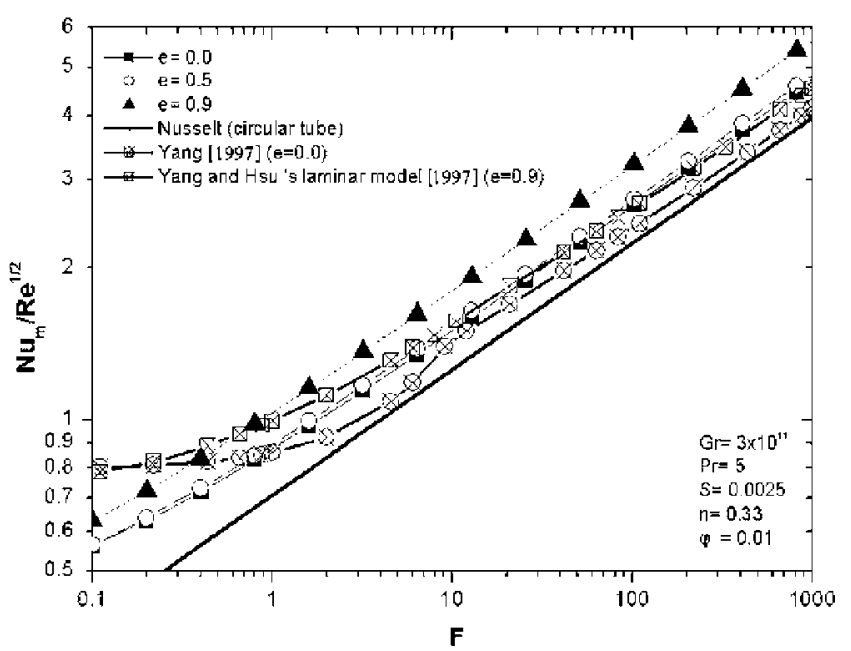

Fig. 6. Effect of $F$ on the mean Nusselt number.

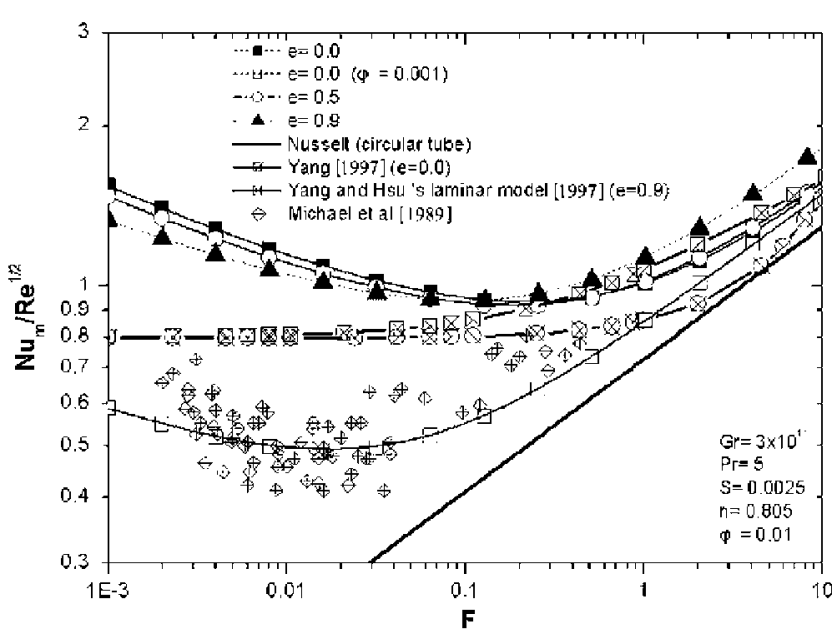

Fig. 7. Effect of $F$ on the mean Nusselt number. 


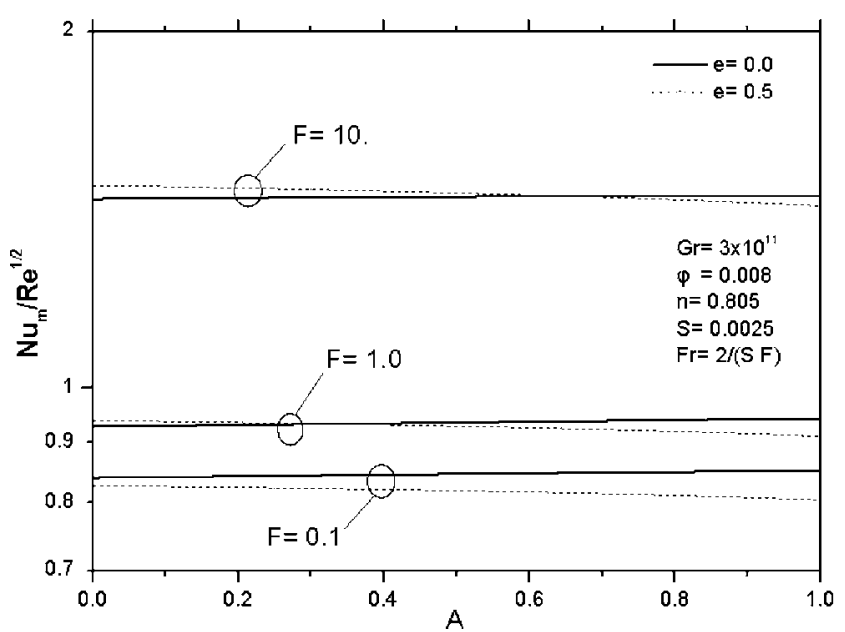

Fig. 8. Dependence of mean Nusselt number on the non-uniform wall temperature variation $\mathrm{A}$.

\section{CONCLUDING REMARKS}

The analytical study of turbulent film condensation on a horizontal elliptical tube has been conducted by using potential flow theory and Colburn analogy for interfacial shear at the interface for high velocity vapors. The following conclusions have been drawn from the present results.

(1) Instead of a fixed value of $n$ (power of Reynolds) in Sarma (1998), we adopt the appropriate values $\mathrm{n}$ for the various film flow velocity (or $F$ ). For lower velocities of vapor flow, the present results coincides with pure laminar model's results or Nusselttype solution better than that in Sarma (1998).

(2) For very high velocities of vapor flow, the present turbulent model also coincides with Michael's experimental data (Michael et al., 1989) better than laminar model's result by Yang and Hsu (1999) and Yang (1997).

(3) The present turbulent model shows a significant downtrend in the mean heat transfer coefficient as increase in $F$ (up to $F=1.0$ ), instead of insignificant variation with $F$ in Yang and Hsu (1999).

(4) The effect of the non-uniform wall temperature variation $A$ on the mean heat transfer coefficient can be ignored regardless the values of $F$.

\section{ACKNOWLEDGEMENT}

Funding for this study was provided by National Science Foundation, Taiwan, R.O.C. under the grant number NSC93-2212-E-151-002.

\section{NOMENCLATURE}

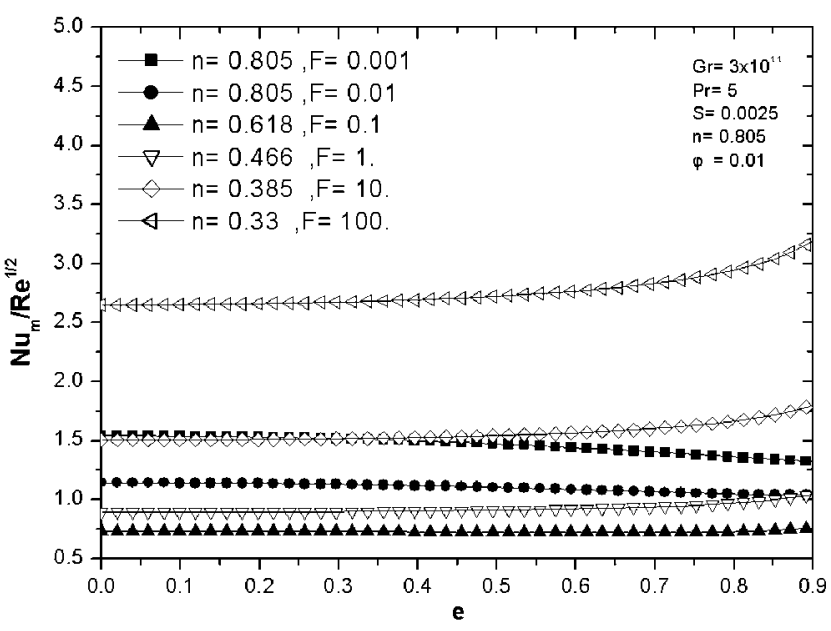

Fig. 9. Effect of e on the mean Nusselt number. $a, b$

$C_{P}$

$e$

F

$\mathrm{Fr}$

$f$

$f_{\phi}$

Gr

$g$

$h$

$h_{f g}$

$k$

$\mathrm{Nu}$

$n$

$\operatorname{Pr}$

$R e_{l}, R e_{v}$

$R e^{*}$

$R e^{+}$

$S$

$T$

$T^{+}$

$u$

$u_{e}$

$u^{*}$

$y^{+}$ semi-major and semi-minor axis of ellipse specific heat of condensate at constant pressure ellipticity of ellipse, $\sqrt{1-(b / a)^{2}}$

dimensionless inverse vapor velocities, 2/ $(F r S)$

Froude number, $u_{\infty}^{2} / g a$

average friction coefficient

local friction coefficient

Grashof number, $\left(\frac{g a^{3}}{v_{l}^{2}}\right)\left(\frac{\rho_{l}-\rho_{v}}{\rho_{l}}\right)$

acceleration due to gravity

local heat transfer coefficient

latent heat of condensate

thermal conductivity of condensate

Nusselt number, $h(2 a) / k_{l}$

the power of Reynolds

Prandtl number, $v / \alpha$

Reynolds number, $u \cdot 2 a / v_{l}, u \cdot 2 a / v_{v}$

shear Reynolds, $\mathrm{Re}^{+} / G r^{1 / 3}$

shear Reynolds parameter, $a u^{*} / v_{l}$

sub-cooling parameter, $C_{P}\left(\bar{T}_{s a t}-\bar{T}_{w}\right) /$ $\left(h_{f g} \operatorname{Pr}\right)$

temperature

dimensionless temperature, $\left(\bar{T}-\bar{T}_{w}\right) /$ $\left(\bar{T}_{s a t}-\bar{T}_{w}\right)$

velocity component in $x$-direction

the tangential vapor velocity at the edge of the boundary layer,

shear velocity, $\left(\tau_{w} / \rho_{l}\right)^{1 / 2}$

coordinate normal to the elliptical wall

dimensionless distance normal to the elliptical wall, $y u^{*} / v_{l}$ 


\section{Greek symbols}

$\delta \quad$ local condensate film thickness

$\delta^{+} \quad$ dimensionless film thickness, $\delta u^{*} / v_{l}$

$\varphi \quad$ interfacial shear parameter,

$$
2^{n} \pi C\left(\frac{\rho_{v}}{\rho_{l}}\right)\left(\frac{v_{l}}{v_{v}}\right)^{n-1} G r^{(3 n-1) / 6}
$$

$\phi$

$\infty$

$\tau$

$v$

$\rho$

$\varepsilon_{M}$

$\varepsilon_{H}$

$\theta$

$\alpha$

\section{Subscripts}

$\begin{array}{ll}l & \text { condensate film } \\ v & \text { vapor } \\ \delta & \text { vapor-liquid interface } \\ w & \text { elliptical tube wall } \\ c & \text { critical condition } \\ \text { sat } & \text { saturation }\end{array}$

\section{Superscripts}

mean values

\section{REFERENCES}

1. Asbik, M., Boushaba, H., Chaynane, R., Zeghmati, B., and Khmou, A., "Prediction of Onset of Boundary Layer Transition in Film Condensation on a Horizontal Elliptical Cylinder," Numer. Heat Transf. Part A: Appl., Vol. 43, pp. 83-109 (2003).

2. Bejan, A., "Turbulent Boundary Layer Flow," Convection Heat Transfer, Vol. 7, 2nd ed., Wiley, New York, pp. 293-324 (1995).

3. Homescu D. and Panday, P.K., "Forced Convection Condensation on a Horizontal Tube: Influence of Turbulence in the Vapor and Liquid Phases," Trans. ASME, Vol. 121, pp. 874-885 (1999).

4. Hsu, C.H. and Yang, S.A., "Pressure Gradient and Variable Wall Temperature Effects during Filmwise Condensation from Downward Flowing Vapors onto a Horizontal Tube," Int .J. Heat Mass Transf., Vol. 42, pp. 2419-2426 (1999).

5. Incropera, F.P. and DeWitt, D.P., "The Cylinder in
Cross Flow," Introduction to Heat Transfer, 2nd ed., Wiley, New York, Vol. 7, pp. 380-381 (1990).

6. Kato, H., Shiwaki, N.N., and Hirota, M., "On the Turbulent Heat Transfer by Free Convection from a Vertical Plate," Int. J. Heat Mass Transf., Vol. 11, pp. 1117-1125 (1968).

7. Lin, Y.T. and Yang, S.A., "Turbulent Film Condensation on a Horizontal Elliptical Tube," Heat Mass Transf., (accepted in 2004).

8. Memory, S.B., Lee, W.C., and Rose, J.W., "Forced Convection Film Condensation on a Horizontal TubeEffect of Surface Temperature Variation," Int. J. Heat Mass Transf., Vol. 36, pp. 1671-1676 (1993).

9. Memory, S.B., Lee, W.C., and Rose, J.W., "Forced Convection Film Condensation on a Horizontal TubeInfluence of Vapor Boundary-Layer Separation," J. Heat Transf., Vol. 117, pp. 529-533 (1995).

10. Michael, A.G., Rose, J.W., and Daniels, L.C., "Forced Convection Condensation on a Horizontal TubeExperiments with Vertical Down-flow of Steam," ASME J. Heat Transf., Vol. 111, pp. $792-797$ (1989).

11. Nusselt, W., "Die Oberflachen Kondensation Des Wasserdampers," Zeitsehrift Desvereines Eutsher Ingenieure, Vol. 60, pp. 541-546 (1916).

12. Rose, J.W., "Effect of Pressure Gradient in Forced Film Condensation on a Horizontal Tube-Effect of Surface Temperature Variation," Int. J. Heat Mass Transf., Vol. 27, pp. 39-47 (1984).

13. Sarma, P.K., Vijayalakshmi, B., Mayinger, F., and Kakac, S., "Turbulent Film Condensation on a Horizontal Tube with External Flow of Pure Vapor," Int. J. Heat Mass Transf., Vol. 41, pp. 537-545 (1998).

14. Shekriladze, I.G. and Gomelauri, V.I., "Theoretical Study of Laminar Film Condensation of Flowing Vapor," Int. J. Heat Mass Transf., Vol. 9, pp. 581-591 (1966).

15. Yang, S.A., "Superheated Laminar Film Condensation on a Nonisothermal Horizontal Tube," J. Thermophys. Heat Transf., Vol. 11, No. 4, pp. 526-532 (1997).

16. Yang, S.A. and Hsu, C.H., "Mixed-Convection Film Condensation on a Horizontal Elliptical Tube with Variable Wall Temperature," J. CSME, Vol. 20, No. 4, pp. 373-384 (1999).

17. Yang, S.A. and Hsu, C.H., "Mixed-convection Film Condensation on a Horizontal Elliptical Tube with Uniform Surface Heat Flux," Numer. Heat Transf. Part A, Vol. 32, pp. 85-95 (1997a).

18. Yang, S.A. and Hsu, C.H., "Free and Forced Convection Film Condensation form a Horizontal Elliptical Tube with a Vertical Plate and Horizontal Tube as Special Cases," Int. J. Heat Fluid Flow, Vol. 18, pp. 567-574 (1997b). 